\title{
Lack of evidence for Litopenaeus vannamei Toll receptor (IToll) involvement in activation of sequence-independent antiviral immunity in shrimp
}

\author{
Yannick Labreuche ${ }^{\mathrm{a},{ }^{*},}$, Nuala A. O'Leary ${ }^{\mathrm{a}}$, Enrique de la Vega ${ }^{\mathrm{a}, 1}$, Artur Veloso $^{\mathrm{a}}$, Paul S. \\ Gross $^{\mathrm{b}, 2}$, Robert W. Chapman ${ }^{\mathrm{c}}$, Craig L. Browdy ${ }^{\mathrm{c}, 3}$ and Gregory W. Warra, c, 4
}

\footnotetext{
a Marine Biomedicine and Environmental Sciences Center, Medical University of South Carolina, 221 Ft. Johnson Road, Charleston, SC 29412, USA

b Department of Biochemistry and Molecular Biology, Medical University of South Carolina, Charleston, SC 29425, USA

c Marine Resources Institute, South Carolina Department of Natural Resources, 217 Ft. Johnson Road, Charleston, SC 29412, USA

${ }^{1}$ Current address: CI OCEANOS, S.A. Carretera a Mamonal No. 1-504 Cartagena, Colombia.

2 Deceased.

${ }^{3}$ Current address: Novus International, 5 Tomotley Ct., Charleston, SC 29407, USA.

${ }^{4}$ Current address: Division of Molecular and Cellular Biosciences, National Science Foundation, Arlington, VA 22230, USA.
}

*: Corresponding author : Current address: IFREMER, Département Lagon, Ecosystèmes et Aquaculture Durable en Nouvelle-Calédonie, BP 2059, 98846 Nouméa Cedex, New Caledonia. Email address : yannick.labreuche@ifremer.fr

\begin{abstract}
:
Injection of non-specific dsRNA initiates a broad-spectrum innate antiviral immune response in the Pacific white shrimp, Litopenaeus vannamei, however, the receptor involved in recognition of this byproduct of viral infections remains unknown. In vertebrates, dsRNA sensing is mediated by a class of Toll-like receptors (TLRs) and results in activation of the interferon system. Because a TLR (IToll) was recently characterized in $L$. vannamei, we investigated its potential role in dsRNA recognition. We showed that injection of non-specific RNA duplexes did not modify IToll gene expression. A reverse genetic approach was therefore implemented to study its role in vivo. Silencing of IToll did not impair the ability of non-specific dsRNA to trigger protection from white spot syndrome virus and did not increase the shrimp susceptibility to viral infection, when compared to controls. In contrast, genespecific dsRNA injected to specifically silence IToll expression activated an antiviral response. These data strongly suggest that shrimp IToll plays no role in dsRNA-induced antiviral immunity.
\end{abstract}

Keywords: DSRNA; Toll-like receptor; Innate immune response; Invertebrate immunity; RNA interference; Virus; Shrimp 


\section{Introduction}

In the shrimp farming industry, the epizootic spread of viral infections has led to huge economic losses, threatening its economic viability and long-term sustainability in some regions of the world [1]. Although control of viral diseases currently represents a great challenge in this industry, little is known in shrimp about immune responses to viruses, when compared to the broad spectrum of knowledge that exists for the vertebrates [2]. In mammals, antiviral immunity relies on several different sensor systems that recognize viral pathogen-associated molecular patterns (PAMPs). Sensing through pattern-recognition receptors (PRR) activates transcription factors (such as nuclear-factor $\mathrm{KB}$, interferon regulatory factor 3 and AP-1), resulting in the secretion of type I interferons (IFNs), proinflammatory cytokines/chemokines, and in the synthesis of antiapoptotic proteins. However it also leads to the activation of several other genes that, in turn, contribute to an antiviral effect via the inhibition of protein synthesis and viral replication [1]. Sensing of viruses by the vertebrate innate immune system is mediated by two different classes of PRR: Toll-like receptors (TLRs), patrolling the extracellular and endosomal compartments [3], and retinoic acidinducible gene I (RIG-I)-like receptors (RLRs) which survey the cytoplasm for the presence of double-stranded RNA (dsRNA ) [4], a molecular structure commonly encountered during the virus replication cycle. Among the $>10$ TLRs identified in mammals, TLR3 is crucial for the recognition of viral dsRNA and its synthetic analog poly(l:C), while each of the other TLRs also initiates immune responses in a ligand-specific manner [3].

For a long time, similar innate responses to dsRNA were assumed to have been absent from invertebrates, mainly because of the lack of invertebrate homologues of IFNs and IFN receptors. These views were reconsidered when Robalino and collaborators demonstrated in the Pacific white leg shrimp L. vannamei that injection of dsRNA of diverse length, sequence, and base composition protected animals from mortality induced by two viruses [5, 6]. Similar results were subsequently obtained in different shrimp species [reviewed in 7]. The discovery that dsRNA triggers a general non-specific antiviral response implies that the shrimp immune system is able to sense viral infections through recognition of dsRNA, and suggests a possible evolutionary link between innate antiviral immunity in vertebrates and invertebrates. To date, the mechanistic details of this phenomenon, including the receptor(s) involved in dsRNA recognition, remain to be explored in penaeid shrimp. Recently, a receptor structurally related to $D$. melanogaster Toll and designated IToll has been characterized for the first time in L. vannamei [8]. This study was therefore aimed at investigating the overall hypothesis that IToll may be involved in dsRNA-induced innate antiviral immunity in shrimp. Specifically, the present work was designed i) to determine whether dsRNA may regulate the expression of IToll and ii) to evaluate the requirement of IToll for the non-specific immune response in vivo using RNA interference.

\section{Materials and methods}

\subsection{Animals and RNA extractions}

L. vannamei shrimp from specific pathogen-free (SPF) lines were used for all experiments. Gills were collected in RNA later reagent (Ambion) and stored at $-20^{\circ} \mathrm{C}$ until use. Total RNA was extracted using RNeasy columns (Qiagen) according to the manufacturer's instructions. RNA quantity, purity and integrity were verified spectrophotometrically $\left(A_{260} / A_{280}\right)$ and by electrophoresis on $1 \%$ agarose gels.

\subsection{Preparation of dsRnA}

Double-stranded RNAs (dsRNA) were generated as previously described [5]. The DNA templates used for in vitro transcription were pCR4 vector (Invitrogen) hosting either a 735-bp portion of shrimp L. vannamei Toll (IToll) cDNA (accession no. DQ923424) or a 200-bp fragment of the 
immunoglobulin (Ig) U H chain of the duck, Anas platyrhynchos (accession no. AJ312200); and pBluescript (Stratagene) hosting a 1,316-bp genomic noncoding region of clone BAC6 from the catfish Ictalurus punctatus IgH locus (accession no. CC936713) referred to in this manuscript as S114. The formation of dsRNA was monitored by determining the size shift in $1 \%$ agarose gel electrophoresis. Duck Ige synthetic siRNAs (GGGTTGCCCATGAGGTTCA) with UU 3' overhangs were purchased from Ambion. Finally, siRNA and dsRNAs were diluted to a final concentration of $250 \mathrm{ng} / \mu \mathrm{l}$ in sterile saline solution $(10 \mathrm{mM}$ Tris $-\mathrm{HCl} \mathrm{pH} \mathrm{7.5,400} \mathrm{mM} \mathrm{NaCl})$ and stored at $-80^{\circ} \mathrm{C}$ until use.

\subsection{Preparation of viral inoculum and experimental infection}

The bioassay system, experimental animals, and white spot syndrome virus (WSSV) inoculum used here have been previously described $[5,9]$. Briefly, $1.0-1.5 \mathrm{~g}$ specific pathogen-free $L$. vannamei shrimp were individually stocked in $260-\mathrm{ml}$ tissue culture flasks with ca. $100 \mathrm{ml}$ of UVsterilized sea water and $100 \%$ daily water exchange, and fed approximately half a pellet of commercial feed every day. After 1-day acclimation, shrimp (30 individual shrimp/treatment) were intramuscularly injected between the third and fourth abdominal segment with $5 \mu \mathrm{g}$ (20 $\mu \mathrm{l}$ volume) of dsRNA (IToll or S114) or sterile saline. After $48 \mathrm{~h}$, animals were injected again with saline or S114 dsRNA mixed with a WSSV inoculum. The WSSV inoculum was prepared as an $L D_{80}$, i.e. the dose that would kill ca. $80 \%$ of infected but otherwise untreated shrimp. Negative controls were injected with S114 dsRNA or saline. Shrimp were kept in culture flasks for 10 days following infection. Cumulative mortality was recorded daily.

\subsection{Quantitative real-time $P C R$}

Quantitative real-time RT-PCR (qPCR) was performed on an ABI 7500 system as previously described [10], to determine the mRNA transcript abundance of each target gene. Briefly, $500 \mathrm{ng}$ of DNAse treated total RNA was reverse transcribed in a $20 \mu \mathrm{l}$ reaction volume using oligo-dT primers and MMLV reverse transcriptase (Promega), according to the manufacturer's instructions. Following reverse transcription, all cDNAs were diluted fourfold in nuclease-free water and stored at $-20^{\circ} \mathrm{C}$. qPCR reactions were performed in duplicate and each contained $4 \mu$ of diluted cDNA (25 ng of total RNA equivalents), 1× QuantiTect ${ }^{\circ}$ SYBR Green PCR master mix buffer (Qiagen) and $300 \mathrm{nM}$ forward and reverse primers in a $25 \mu \mathrm{l}$ reaction volume. The amplification profile consisted of an initial denaturation step at $95^{\circ} \mathrm{C}$ for $15 \mathrm{~min}$ and then 40 cycles of $95^{\circ} \mathrm{C}$ for $10 \mathrm{~s}$, $59^{\circ} \mathrm{C}$ for $30 \mathrm{~s}$ and $72^{\circ} \mathrm{C}$ for $32 \mathrm{~s}$ followed by a dissociation stage according to the manufacturer's instructions. Amplification efficiencies for all qPCR primers were determined according to [11] and the specificity of the PCR amplification verified from the melting curve. Each run included the cDNA control, negative controls (total RNA treated with DNase I), and blank controls (water). The relative mRNA expression levels were determined using the two standard curve methodology (QuantiTect ${ }^{\circledR}$ SYBR Green PCR Handbook) and S3A ribosomal protein (GenBank accession no. BF023924) was used as the internal reference (normaliser) mRNA. Specific primers for S3A and IToll were S3A F (5'-GGC TTG CTA TGG TGT GCT CC-3'), S3A R (5'-TCA TGC TCT TGG CTC GCT G-3') and IToll F (5'-TCT GCT GAC GAA TAC TCC CAA AC-3'), IToll R (5'-GAC TGC CCA CGC GAT TTC-3'), respectively.

\subsection{Statistical analyses}

All numerical data were expressed as the mean \pm standard error. Differences in mortality levels between treatments were analyzed by Kaplan-Meier log-rank $x 2$ tests using GraphPad Prism 3.00 for Windows (GraphPad Software, USA) computer software. One-way analysis of variance (ANOVA) or the Kruskal-Wallis test was used for mRNA expression analysis. These statistical analyses were performed with Statgraphics Plus 5.0 software. 


\section{Results and discussion}

L. vannamei IToll presents all the characteristic domains of Toll-like receptor proteins: an extracellular amino-terminal leucine-rich repeat (LRR) region and an intracellular carboxyl terminal Toll/interleukin-1 receptor (TIR) domain [2, 8]. Moreover, it displays high similarity, in terms of amino acid sequences and domain architecture, with Toll-like receptors characterized in other invertebrates, such as the fruit fly D. melanogaster Toll (dToll) [12]. Despite this apparent conservation of innate immune signaling, and the observation that shrimp respond to many of the same microbe-associated molecular structures to which vertebrates are sensitive (e.g. dsRNA [5], peptidoglycans [13], LPS [14], glucans [15]), the hypothesis that IToll may be a molecular component for the cellular recognition of dsRNA has remained essentially untested.

Experiments were therefore conducted in shrimp to explore the possible role of IToll in recognition of microbial ligands. Because exogenous addition of synthetic dsRNA has been demonstrated in various mammalian cell types to up regulate expression of TLR leading to the activation of an innate immune response [reviewed in 16], we monitored IToll relative expression in shrimp following injection with duck Igv siRNAs. As indicated in Fig. 1, stimulation by non-specific siRNAs did not cause any significant change in IToll mRNA level, as assessed by comparison with shrimp injected with saline only (ANOVA, $P>0.05$ ). Because several studies in mammals using different sizes of poly $(\mathrm{I}: \mathrm{C}$ ) (a synthetic ligand mimicking viral dsRNA) indicated that longer duplexes are more potent inducers of TLR3 signaling $[17,18]$, we also explored if similar size limits may apply in shrimp by stimulating animals with 200-bp duck Ige dsRNAs. Data presented in Fig. 1 demonstrated that, similarly to short RNA duplexes, longer dsRNA did not induce any significant modification of IToll mRNA abundance. In vertebrates, TLR regulation on the transcriptional level is suspected to represent an important aspect of TLR immunological function. For instance, it has been shown in mice that interleukin- 6 secretion upon challenge with LPS was directly proportional to the number of TLR4 transgene copies [19]. Moreover, different viruses were reported to augment TLR3 expression, this up-regulation sensitizing the cells to subsequent viral or dsRNA exposure and enhancing IFN- $\beta$ secretion $[20,21]$. Collectively, expression data obtained in this study demonstrate that, contrary to mammalian TLR3, IToll expression pattern is not responsive to dsRNA and thus suggest that this receptor may not act as a sentinel for dsRNA-induced responses in shrimp.

To further test this hypothesis, the ability of IToll to trigger sequence-independent antiviral immunity following stimulation by dsRNA was evaluated in in vivo conditions using RNA interference. To this end, animals were first injected with IToll sequence-specific dsRNA followed by subsequent infection ( $48 \mathrm{~h}$ later) with an inoculum of WSSV, a complex enveloped dsDNA virus, mixed with S114 dsRNA. We reasoned that, if IToll was responsible for dsRNA-induced antiviral immunity, injection of IToll-silenced shrimp with non-specific dsRNA would not elicit protection from a concomitant WSSV infection. As a control, animals were injected with S114 dsRNA and subsequently with a mixture of S114 dsRNA and WSSV. In the course of this experiment, we first checked that IToll message was successfully down-regulated using sequence-specific long dsRNA. As shown in Fig. 2 a, intramuscular injection of IToll sequence-specific dsRNA resulted in a statistically significant depletion of cognate mRNA levels, as determined by qPCR. Depletion was restricted to injection with IToll dsRNA, with no suppression of IToll expression occurring in control animals. As summarized in Fig. 2 b, injection of S114 dsRNA resulted in significantly increased survival to WSSV infection (Kaplan-Meier log-rank $X 2$ : 21.95, $\mathrm{P}<0.0001$ ), confirming previously obtained results [5]. No statistically significant increase in mortality was observed for shrimp in which IToll had been first knocked down, compared to S114 dsRNA-injected animals over the 9day period after viral infection $(P>0.05)$. This observation is consistent with the observed lack of IToll transcriptional regulation following dsRNA stimulation and suggests that IToll plays little to no role in the dsRNA-induced innate antiviral immunity of shrimp. Finally, confirmation that this shrimp TLR was not involved in the general antiviral response was sought by challenging IToll-knockdown shrimp with WSSV only. As indicated in Fig. 2 b, IToll silencing induced by the injection of specific dsRNA did not increase the shrimp susceptibility to WSSV infection $(P>0.05)$. Indeed, shrimp that received the IToll dsRNA showed $26.7 \%$ mortality by day 9 post infection as compared to $33.3 \%$ 
mortality in the control groups that had received S114 dsRNA. These data demonstrate that sequence-specific dsRNA initially injected to silence IToll expression triggered a non-specific antiviral response in IToll knockdown animals (Kaplan-Meier log-rank X2: 29.55, P < 0.0001), as it has been observed before for dsRNAs targeting other shrimp genes [6].

In mammalian systems, multiple TLRs have been found that activate the immune response via detection of a range of PAMPs [2, 3]. In contrast, of the 10 TLRs characterized in D. melanogaster, only one has been shown to play a role in bacterial, fungal and viral immune response [22]. To date, 3 TLRs designated PmToll, FcToll and MjToll have been identified in shrimp Penaeus monodon, Fenneropenaeus chinensis and Marsupenaeus japonicus, respectively [23, 24, 25]. Information about their function in innate immune responses is relatively sparse and comes only from expression analyses. Expression of MjToll was shown to increase following stimulation with peptidoglycan but not with poly (I:C) [24]. Similarly, analysis of PmToll expression in WSSVinfected animals did not reveal any differential regulation of its transcription [23]. Finally, FcToll expression indicated that it may be inducible after bacterial challenge and participate in shrimp bacterial immune responses [25]. Collectively, data obtained in this study provide several lines of evidence arguing against the role of IToll as a dsRNA receptor and also against its involvement in dsRNA-induced antiviral immunity in L. vannamei. Thus, of the 4 TLRs characterized so far in penaeid shrimp, none of them have demonstrated to respond to dsRNA stimulation and/or viral infection. In the absence of fully-sequenced genomes in shrimp, we can not rule out the hypothesis that other members of the TLR family may exist in shrimp, as it has been reported in other invertebrates such the mosquito [26] or the sea urchin [27].

Alternatively, this general non-specific antiviral response in shrimp may rely on a TLR independent signaling pathway. If viral dsRNA is known to be recognized by TLR3 in vertebrates, other mechanisms for dsRNA sensing have also been identified, that involve different components, such as dsRNA-dependent protein kinase R (PKR), 2'-5' oligoadenylate synthetases, and retinoic acidinducible gene I (RIG-I)/melanoma differentiation-associated gene 5(MDA5), which differ in their cellular localizations and downstream signaling pathways for the induction of type I IFNs [2, 4]. Although searches of known invertebrate genomes have not yet yielded homologues for these components (or for interferon-like genes), growing evidence for specific immune memory in crustacea, including shrimp, suggest that novel antiviral immune pathways may operate in invertebrates $[6,28]$. To date, dozens of shrimp genes for which no identifiable homologues exist but whose expression is modified in response to viral infections have been found by transcriptomic analyses [29, 30, 31]. They warrant future investigation, as they may contribute to the characterization of dsRNA-sensing PRR and more generally to our understanding of dsRNAinduced innate antiviral immunity.

\section{Acknowledgments}

This research was funded by awards from the National Science Foundation (MCB-0315393; MCB0624271), the National Marine Fisheries Service (NA03NMF472O362), the USDA (NRICREES 2006-01605 and the U.S. Marine Shrimp Farming Program), by a Marine Genomics fellowship support from the College of Charleston to A.V. and through the support of the NOAA Center of Excellence in Oceans and Human Health at the Hollings Marine Laboratory. This is publication \#49 for the Marine Genomics Program of the Marine Biomedicine and Environmental Sciences program at MUSC and \#651 from the Marine Resources Division of the South Carolina Department of Natural Resources. We warmly thank members of the Marine Infectious Disease Laboratory at the South Carolina Department of Natural Resources for help with rearing and challenging shrimp. Any opinions, findings, and conclusions or recommendations expressed in this material are those of the author(s) and do not necessarily reflect the views of the supporting bodies mentioned herein. 


\section{References}

[1] Lightner, D.V., and Redman, R.M. Shrimp diseases and current diagnostic methods. Aquaculture 1998; 164: 201-20.

[2] Takeuchi, O. and Akira, S. Innate immunity to virus infection. Immunol Rev. 2007; 220:214-24.

[3] Werling D, Jungi TW. Toll-like receptors linking innate and adaptive immune response. Vet Immunol Immunopathol. 2003; 91(1):1-12.

[4] Saito T. and Gale M. Jr. Differential recognition of double-stranded RNA by RIG-I-like receptors in antiviral immunity. J Exp Med. 2008; 205(7):1523-7.

[5] Robalino J, Browdy CL, Prior S, Metz A, Parnell P, Gross P, Warr G. Induction of antiviral immunity by double-stranded RNA in a marine invertebrate. J Virol. 2004; 78(19):10442-8.

[6] Robalino J, Bartlett TC, Chapman RW, Gross PS, Browdy CL, Warr GW. Double-stranded RNA and antiviral immunity in marine shrimp: inducible host mechanisms and evidence for the evolution of viral counter-responses. Dev Comp Immunol. 2007;31(6):539-47.

[7] Shekhar, M.S., and Lu, Y. (2008) Application of nucleic-acid-based therapeutics for viral infections in shrimp aquaculture. Mar Biotechnol (NY). In press.

[8] Yang LS, Yin ZX, Liao JX, Huang XD, Guo CJ, Weng SP, Chan SM, Yu XQ, He JG. A Toll receptor in shrimp. Mol Immunol. 2007; 44(8):1999-2008.

[9] Prior, S., C. L. Browdy, E. F. Shepard, R. Laramore, and P. G. Parnell. Controlled bioassay systems for determination of lethal infective doses of tissue homogenates containing Taura syndrome or white spot syndrome virus. Dis. Aquat. Organ 2003; 54: 89-96.

[10] de la Vega, E., O'Leary, N.A., Shockey, J.E., Robalino, J., Payne, C., Browdy, C.L., Warr, G.W., and Gross, P.S. Anti-lipopolysaccharide factor in Litopenaeus vannamei (LVALF): A broad spectrum antimicrobial peptide essential for shrimp immunity against bacterial and fungal infection. Mol. Immunol. 2008; 45: 1916-25.

[11] Pfaffl, M.W., Horgan, G.W., Dempfle, L. Relative expression software tool (REST(C) for groupwise comparison and statistical analysis of relative expression results in real-time PCR. Nucl. Acids Res. 2002; 30 (9) e36.

[12] Tauszig, S., Jouanguy, E., Hoffmann, J.A., Imler, J.L. Toll-related receptors and the control of antimicrobial peptide expression in Drosophila. Proc. Natl. Acad. Sci. U.S.A 2000; 97: 1052010525.

[13] Fagutao FF, Yasuike M, Caipang CM, Kondo H, Hirono I, Takahashi Y, Aoki T. Gene expression profile of hemocytes of kuruma shrimp, Marsupenaeus japonicus following peptidoglycan stimulation. Mar Biotechnol (NY). 2008; 10(6):731-40.

[14] Okumura T. Effects of lipopolysaccharide on gene expression of antimicrobial peptides (penaeidins and crustin), serine proteinase and prophenoloxidase in haemocytes of the Pacific white shrimp, Litopenaeus vannamei. Fish Shellfish Immunol. 2007; 22(1-2):68-76.

[15] Wang YC, Chang PS, Chen HY. Differential time-series expression of immune-related genes of Pacific white shrimp Litopenaeus vannamei in response to dietary inclusion of beta-1,3-glucan. Fish Shellfish Immunol. 2008; 24(1):113-21.

[16] Matsumoto $M$ and Seya T. TLR3: interferon induction by double-stranded RNA including poly(I:C). Adv Drug Deliv Rev. 2008; 60(7):805-12.

[17] de Bouteiller O, Merck E, Hasan UA, Hubac S, Benguigui B, Trinchieri G, Bates EE, Caux C. Recognition of double-stranded RNA by human toll-like receptor 3 and downstream receptor signaling requires multimerization and an acidic pH. J Biol Chem. 2005; 280(46):38133-45.

[18] Okahira S, Nishikawa F, Nishikawa S, Akazawa T, Seya T, Matsumoto M. Interferon-beta induction through toll-like receptor 3 depends on double-stranded RNA structure. DNA Cell Biol. 2005; 24(10):614-23.

[19] Kalis, C., Kanzler, B., Lembo, A., Poltorak, A., Galanos, C., and Freudenberg, M. A. Toll-like receptor 4 expression levels determine the degree of LPS-susceptibility in mice. Eur. J. Immunol. 2003; 33 (3): 798-805

[20] Groskreutz, D. J., M. M. Monick, L. S. Powers, T. O. Yarovinsky, D. C. Look, and G. W. Hunninghake. Respiratory syncytial virus induces TLR3 protein and protein kinase R, leading to 
increased double-stranded RNA responsiveness in airway epithelial cells. J. Immunol. 2006; 176:1733-1740

[21] Tanabe, M., M. Kurita-Taniguchi, K. Takeuchi, M. Takeda, M. Ayata, H. Ogura, M. Matsumoto, and T. Seya. Mechanism of up-regulation of human Toll-like receptor 3 secondary to infection of measles virus-attenuated strains. Biochem. Biophys. Res. Commun. 2003; 311 (1):39-48

[22] Zambon RA, Nandakumar M, Vakharia VN, Wu LP. The Toll pathway is important for an antiviral response in Drosophila. Proc Natl Acad Sci U S A. 2005;102(20):7257-62.

[23] Arts JA, Cornelissen FH, Cijsouw T, Hermsen T, Savelkoul HF, Stet RJ. Molecular cloning and expression of a Toll receptor in the giant tiger shrimp, Penaeus monodon. Fish Shellfish Immunol. 2007; 23(3):504-13.

[24] Mekata T, Kono T, Yoshida T, Sakai M, Itami T. Identification of cDNA encoding Toll receptor, MjToll gene from kuruma shrimp, Marsupenaeus japonicus. Fish Shellfish Immunol. 2008; 24(1):122-33.

[25] Yang C, Zhang J, Li F, Ma H, Zhang Q, Jose Priya TA, Zhang X, Xiang J. A Toll receptor from Chinese shrimp Fenneropenaeus chinensis is responsive to Vibrio anguillarum infection. Fish Shellfish Immunol. 2008; 24(5):564-74.

[26] Luna C, Hoa NT, Zhang J, Kanzok SM, Brown SE, Imler JL, Knudson DL, Zheng L. Characterization of three Toll-like genes from mosquito Aedes aegypti. Insect Mol Biol. 2003; 12(1):67-74.

[27] Rast JP, Smith LC, Loza-Coll M, Hibino T, Litman GW. Genomic insights into the immune system of the sea urchin. Science 2006; 314(5801):952-6.

[28] Johnson, K.N., van Hulten, M.C.W., and Barnes, A.C. "vaccination" of shrimp against viral pathogens: Phenomenology and underlying mechanisms. Vaccine 2008; 26: 4885-92.

[29] Dhar, A.K., Dettori, A., Roux, M.M., Klimpel, K.R., Read, B. Identification of differentially expressed genes in shrimp (Penaeus stylirostris) infected with White spot syndrome virus by cDNA microarrays. Arch. Virol. 2003; $148: 2381-2396$.

[30] Wang, B., Li, F., Dong, B., Zhang, X., Zhang, C., Xiang, J. Discovery of the genes in response to white spot syndrome virus (WSSV) infection in Fenneropenaeus chinensis through cDNA microarray. Mar. Biotechnol. (NY) 2006; 8:491-500.

[31] Pongsomboon S, Tang S, Boonda S, Aoki T, Hirono I, Yasuike M, Tassanakajon A. Differentially expressed genes in Penaeus monodon hemocytes following infection with yellow head virus. BMB Rep. 2008; 41(9):670-7. 


\section{Figures}

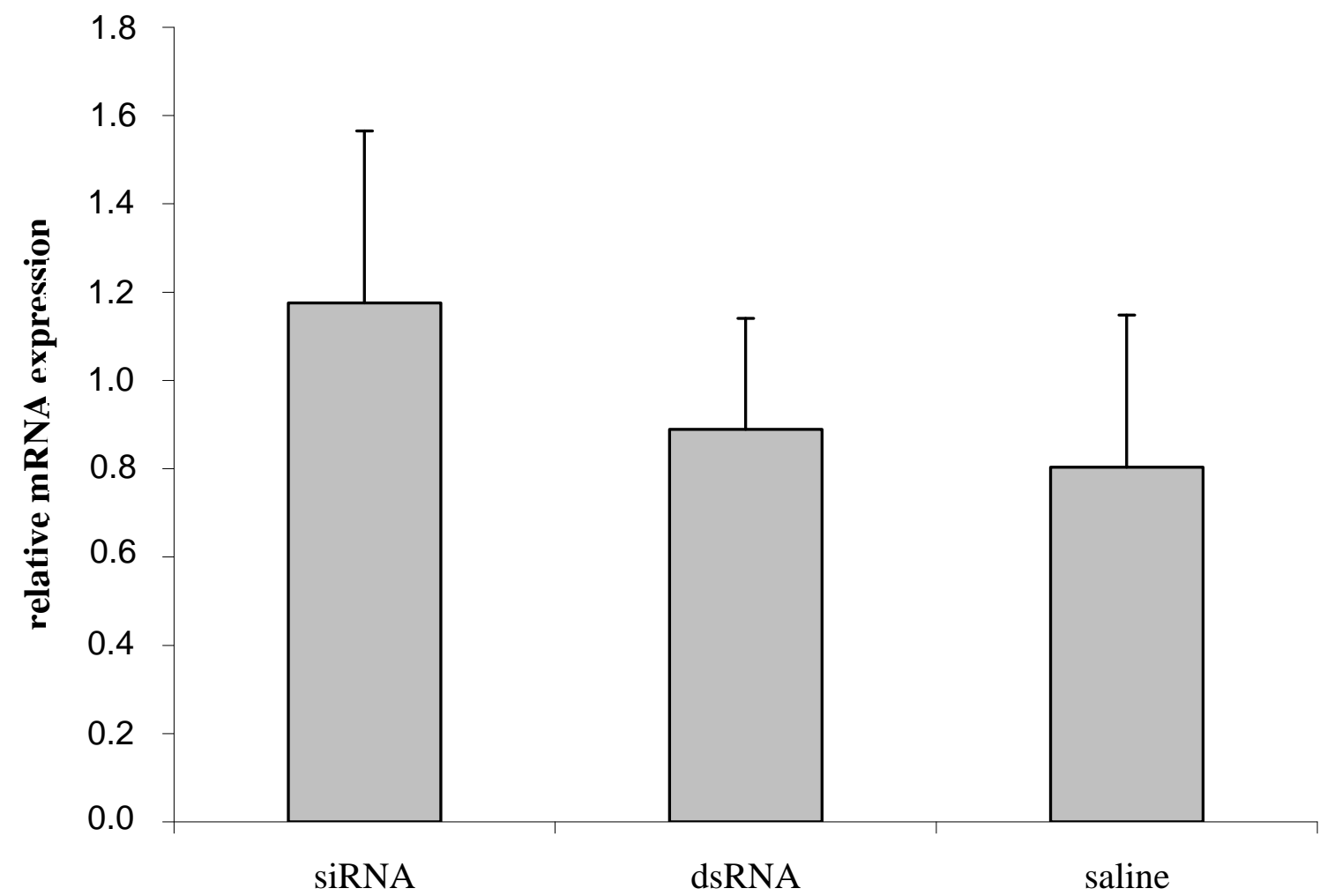

Fig. 1.

Fig. 1. IToll mRNA transcript abundance. Shrimp (1 to $1.5 \mathrm{~g}, n=30$ ) were injected intramuscularly with saline, $5 \mu \mathrm{g}$ of duck Igv dsRNA or $5 \mu \mathrm{g}$ of duck $\lg v$ siRNA. At $48 \mathrm{~h}$ after this initial injection, 5 animals were randomly sampled in each group and IToll expression was determined in gill tissues of each individual shrimp by qPCR. Injection of siRNA or dsRNA did not cause any significant change $(P>0.05)$ in IToll mRNA levels. Expression values (shown as means \pm standard error) are presented as relative abundance in relation to S3A ribosomal gene. 

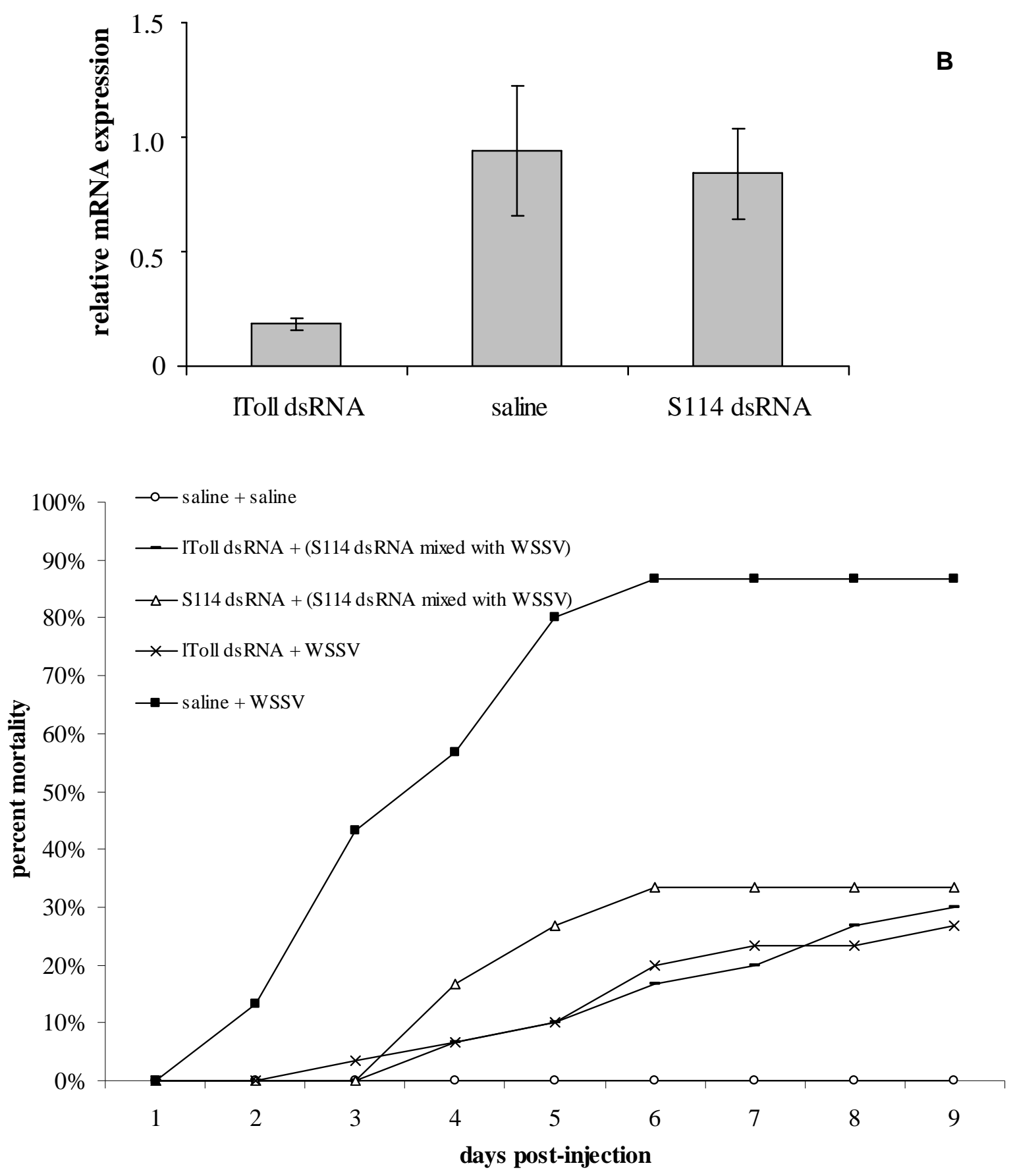

Fig. 2.

Fig. 2. A) IToll transcript abundance in shrimp gills following treatment with dsRNA. Shrimp were injected on day 0 with saline, $5 \mu \mathrm{g}$ of IToll dsRNA or S114 dsRNA as a sequence-independent dsRNA. Intramuscular injection of gene-specific dsRNA resulted in a statistically significant reduction in IToll mRNA levels $(P<0.05)$. Expression values determined by quantitative real-time qPCR are presented as relative abundance in relation to S3A ribosomal gene. Bars represent \pm standard error of the mean. B) Shrimp mortality following injection with dsRNA and experimental infection with WSSV. Shrimp $(n=30)$ were injected intramuscularly with either saline (positive [ $\square]$ and negative [O] controls) or dsRNA (IToll or S114). At $48 \mathrm{~h}$ after this initial injection, animals were infected with WSSV either alone or mixed with S114 dsRNA. Differences in mortality levels between treatments were analyzed by Kaplan-Meier log-rank $X 2$ tests. Protection from viral infection in dsRNA-treated groups (IToll or S114) was observed until 9 dpi $(P<0.0001)$. 